\title{
Psychosocial and physical risk factors for musculoskeletal disorders of the neck, shoulders, and lower back in salespeople
}

\author{
Torsten Skov, Vilhelm Borg, Elsa Ørhede
}

\begin{abstract}
Objectives-To analyse the association between symptoms from the musculoskeletal system and many psychosocial and other physical stressors in the job demand-control-support model. Also to analyse the influence of personality characteristics.

Methods-1306 salespeople answered a self administered questionnaire on job characteristics, exposures, personality characteristics, social network, smoking and drinking habits, and symptoms of the neck, shoulders, and low back.

Results-In multivariate analyses, high job demands were related to neck and shoulder symptoms (ORs 1.43-1.47 in the highest exposure groups compared with the lowest), and tendency to become overworked and lack of social support from colleagues were related to back pain (OR 1.81-2.04 in the highest exposure groups compared with the lowest). Lack of variation in the job, low control over time, and high competition were related to neck symptoms, but there was an interaction so that both low control over time and high competition had to be present to increase the OR. Also, driving long distances and sedentary work were related to neck and low back pain, and time spent in the car to shoulder pain (ORs 1.64-2.80 in the three highest groups $v$ the lowest exposure groups).

Conclusion-Both psychosocial and physical factors were associated with musculoskeletal symptoms. Many dimensions of the demand-control-support model were associated with symptoms. Only one personality characteristic, tendency to feel overworked, significantly influenced the prevalence of musculoskeletal symptoms.
\end{abstract}

(Occup Environ Med 1996;53:351-356)

National Institute of Occupational Health, Lersø Parkallé 105, DK-2100 København б, Denmark

T Skov

V Borg

E Ørhede

Correspondence to:

Dr Torsten Skov, National Institute of Occupational Institute of Occupational DK-2100 København $\emptyset$, DK-2100

Accepted 15 December 1995
Keywords: decision latitude; job demand-controlsupport model; driver; sedentary work

For reasons only partly understood, muscucommon in western countries during the past decades. Physical loads such as repetitive heavy lifting especially in twisted positions, and motor vehicle driving are established risk factors for back pain. ${ }^{1}$ Sustained static load and repetitiveness are established risk factors for neck and shoulder disorders. ${ }^{2}$ loskeletal disorders have become increasingly
During the past few years the contribution of psychosocial stressors to the occurrence of musculoskeletal disorders has become increasingly clear. The job demand-control-support model, which has been widely used as a model for relations between the psychosocial work environment and cardiovascular disease, ${ }^{3}$ has also been introduced in studies of musculoskeletal disorders. A recent review of publications on psychosocial factors at work and musculoskeletal disease ${ }^{4}$ concluded that high job demands have consistently been associated with musculoskeletal symptoms. Furthermore, the data indicated that lack of control and lack of social support at work are positively associated with musculoskeletal disorders.

In most studies only one or a few psychosocial factors have been taken into account simultaneously. Bongers et $\mathrm{al}^{4}$ noted that no studies existed of back trouble which analysed the effect of demands, control, and social support at the same time. It was also noted that several studies did not control appropriately for physical load. As high psychosocial job demands are often correlated with high physical load, it could be argued that the associations found for the psychosocial factors were due to residual confounding from the physical factors.

In a population based study of patients who consulted a physician for neck and shoulder disorders, the work organisation and the psychosocial work conditions were as important determinants for disease as were the physical work conditions. ${ }^{5}$ Similar findings were reported in a group of newspaper workers, ${ }^{6}$ and a study of a population sample from Holland. ${ }^{7}$

A person's way of coping with a potential stressor in the work environment could determine whether or not the stressor will have an adverse effect. ${ }^{8}$ Evidence of such effect modification is missing for musculoskeletal disorders, but some studies have suggested an association between type $A$ behaviour and neck, shoulder, and low back pain. ${ }^{49}$

We did a study among salespeople. Many salespeople experience high job demands and competition with other salespeople. They work outside the company in which they are employed, and have little contact with colleagues. On the other hand, many salespeople have a high degree of control over and variation in the job. The physical exposures in the job include prolonged driving, sedentary work, and among some subgroups lifting of heavy loads. Thus, salespeople are a suitable group for estimating the effects of a range of psy- 
chosocial and physical exposures, each controlled for the possible confounding effects of the others.

The primary objective of the study was to test the variables of the job demands-controlsupport model, including possible modification of effect (interaction) between demands and control.

A secondary objective was to test whether personality characteristics modified the associations between psychosocial stressors at work and musculoskeletal symptoms.

Many other variables were included in the analyses, mainly to obtain unconfounded results for above mentioned objectives. These were, for example, social network in private life, uncertainty of employment prospects, and work role. Also physical exposures such as lifting, sitting, and driving long distances were included.

\section{Material and methods}

A questionnaire was posted to a random $8 \%$ sample of the members of the association Danish Active Salespeople. The 1991 questionnaires were sent, and $1306(66 \%)$ were returned completed. Of the salespeople $3 \%$ declined to participate, $3 \%$ returned a blank questionnaire, $3 \%$ said that they were unemployed or no longer salespeople, and $25 \%$ did not respond at all.

\section{DEFINITION OF OUTCOME}

Musculoskeletal symptoms were ascertained with the Nordic questionnaire on musculoskeletal disorders supplemented with a question on the intensity of symptoms on a 10 point scale ranging from none to very, very intense. ${ }^{10}$ For the present analyses outcomes were defined as symptoms (tenderness, pain, discomfort) during the past 12 months from the body region in question (neck, shoulders, low back). People who reported trauma to the given body region were excluded. Preliminary analyses showed that the symptom intensity was not associated with the exposure intensity. Therefore the symptom intensity was not included in the definition of the outcome.

\section{EXPOSURES}

Questions were asked about the annual driving distance, time in sedentary work, car equipment and price, and lifting of heavy loads. Leisure time sports activities were also ascertained.

The psychosocial job characteristics were assessed with questions on demands, control, and social support ${ }^{112}$ supplemented with questions on perceived competition from other salespeople developed for this study, role conflict, ${ }^{13}$ and uncertainty of employment

Table 1 Age and prevalences of symptoms in the past 12 months

\begin{tabular}{llllll}
\hline & & $\begin{array}{l}\text { Age } \\
\text { mean } \\
(S D)\end{array}$ & $\begin{array}{l}\text { Neck } \\
\%\end{array}$ & $\begin{array}{l}\text { Shoulders } \\
\%\end{array}$ & $\begin{array}{l}\text { Low back } \\
\%\end{array}$ \\
\hline Men & 1167 & $42 \cdot 0(9 \cdot 9)$ & 54 & 35 & 63 \\
Women & 137 & $36 \cdot 5(7 \cdot 8)$ & 76 & 47 & 64 \\
\hline
\end{tabular}

prospects. ${ }^{14} \mathrm{~A}$ factor analysis (discussed later) identified 11 factors.

The first two were concerned with the demand part of the demand-control-support model:

- job demands (especially items like high demands for concentration and speed in the work)

-perception of competition (with salespeople from other companies).

Two other factors were concerned with the control part of the demand-control-support model:

- control over the content of the job

- control over time aspects of the work (items like deciding working hours, holidays).

Two factors were concerned with the support part of the demand-control-support model:

- social contact and support from colleagues -support from superiors.

Five factors were concerned with other aspects of the psychosocial work environment:

-uncertainty of employment prospects (being concerned that one may become unemployed, transferred to another job, etc)

-conflicts with colleagues

-work role ambiguity (unclearly defined demands in the work)

-work role conflict (conflicting demands in the work)

-variation in the work.

The social network outside the job was assessed with questions originally developed for the Alameda study, in the Nordic countries. ${ }^{15}$ The factors concerning social network were:

-contact with the social network

-influence on people in the social network

-feeling accepted by people in the social network

-feeling close to people in the social network

-feeling that one is part of a larger social network.

Personality characteristics were assessed with questions obtained from J Siegrist and translated into Danish. ${ }^{16}$ These were:

- tendency to become overworked

- confronting attitude toward other people

-individualistic attitude

-tendency to be late

-ambitious attitude

-acceptance seeking

- sensitive to interruptions.

Finally, other variables used in the analysis included sex, type of product sold, weekly working hours, time spent with customers, number of nights spent away from the home, type of wage earning system, smoking (passive and active), weight, height, and age.

\section{STATISTICAL ANALYSES}

Factor analysis was used. Varimax rotation was used to find the most obvious factors. Variables with factor loadings above 0.40 were included in the factors. Responses were summed to form a joint score on each factor. The scores were grouped into empirical quartiles which were used in the tabulations as well as regressions. For control over time and per- 
Table 2 Symptoms of the neck during the past 12 months (final main effects model)

\begin{tabular}{|c|c|c|c|c|c|}
\hline Factors: variables & OR & $(95 \% C I)$ & $\begin{array}{l}P \text { value for } \\
\text { logistic } \\
\text { regression }\end{array}$ & $P P R$ & $(95 \% C I)$ \\
\hline Sex: & & & 0.000 & & \\
\hline Men & 1 & & & & \\
\hline Women & $2 \cdot 76$ & $(1 \cdot 72-4 \cdot 43)$ & & $1 \cdot 39$ & $(1 \cdot 10-1 \cdot 75)$ \\
\hline Annual driving distance $(\mathrm{km})$ : & & & 0.011 & & \\
\hline$<5000$ & & & & & \\
\hline $5-10000$ & 0.99 & $(0 \cdot 45-2 \cdot 2)$ & & 0.99 & $(0 \cdot 55-1 \cdot 76)$ \\
\hline $10-15000$ & 1.48 & $(0.75-2.93)$ & & $1 \cdot 20$ & $(0.74-1.92)$ \\
\hline $15-30000$ & 1.74 & $(1 \cdot 01-2 \cdot 99)$ & & $1 \cdot 29$ & $(0 \cdot 88-1 \cdot 89)$ \\
\hline $30-50000$ & $2 \cdot 10$ & $(1 \cdot 24-3 \cdot 54)$ & & 1.39 & $(0.96-2.00)$ \\
\hline$>50000$ & $2 \cdot 43$ & $(1 \cdot 36-4 \cdot 34)$ & & 1.46 & $(0 \cdot 99-2 \cdot 17)$ \\
\hline Sedentary work (proportion of & & & & & \\
\hline $\begin{array}{l}\text { work time): } \\
\text { None or infrequently }\end{array}$ & 1 & & 0.018 & & \\
\hline $\begin{array}{l}\text { None or infrequently } \\
1\end{array}$ & $2 \cdot 68$ & $(1 \cdot 31-5 \cdot 49)$ & & 1.62 & $(0 \cdot 95-2 \cdot 75)$ \\
\hline$\frac{1}{1}$ & 1.92 & $(0.98-3.79)$ & & 1.42 & $(0 \cdot 85-2 \cdot 37)$ \\
\hline 3 & $2 \cdot 18$ & $(1 \cdot 11-4 \cdot 29)$ & & 1.49 & $(0 \cdot 89-2 \cdot 48)$ \\
\hline All & $2 \cdot 80$ & $(1.40-5 \cdot 59)$ & & $1 \cdot 64$ & $(0 \cdot 98-2 \cdot 75)$ \\
\hline Demands in the work (quartiles): & & & 0.033 & & \\
\hline Lowest & 1 & & & & \\
\hline Next to lowest & $0 \cdot 84$ & $(0 \cdot 6-1 \cdot 19)$ & & 0.92 & $(0 \cdot 73-1 \cdot 16)$ \\
\hline Next to highest & $1 \cdot 13$ & $(0 \cdot 8-1 \cdot 59)$ & & 1.05 & $(0 \cdot 84-1 \cdot 31)$ \\
\hline Highest & 1.43 & $(0.99-2.06)$ & & $1 \cdot 14$ & $(0 \cdot 91-1 \cdot 43)$ \\
\hline Variation in the work (quartiles): & & & 0.010 & & \\
\hline Highest & 1 & & & 1 & \\
\hline Next to highest & $1 \cdot 78$ & $(1 \cdot 16-2 \cdot 73)$ & & $1 \cdot 30$ & $(0.98-1 \cdot 73)$ \\
\hline Next to lowest & 1.36 & $(0.95-1.96)$ & & $1 \cdot 16$ & $(0.90-1.50)$ \\
\hline Lowest & 1.82 & $(1 \cdot 23-2.69)$ & & $1 \cdot 31$ & $(1 \cdot 01-1 \cdot 70)$ \\
\hline Control over time (quartiles): & & & 0.046 & & \\
\hline High (top two quartiles) & 1 & & & 1 & \\
\hline Medium & 1.09 & $(0 \cdot 8-1 \cdot 5)$ & & $1 \cdot 04$ & $(0 \cdot 84-1 \cdot 29)$ \\
\hline Low & 1.44 & $(1.07-1.93)$ & & $1 \cdot 15$ & $(0 \cdot 96-1 \cdot 39)$ \\
\hline Perceived competition (quartiles): & & & 0.033 & & \\
\hline Low & 1 & & & 1 & \\
\hline Medium & $1 \cdot 38$ & $(0.98-1.93)$ & & $1 \cdot 15$ & $(0 \cdot 92-1 \cdot 43)$ \\
\hline High (top two quartiles) & $1 \cdot 44$ & $(1.08-1.91)$ & & $1 \cdot 16$ & $(0 \cdot 96-1 \cdot 40)$ \\
\hline
\end{tabular}

Table 3 Neck symptoms during the past 12 months (ORs (95\% CIs) for the interacting variables control over time and perceived competition from other salesmen: $P$ value for the interaction $=0.016$ )

\begin{tabular}{lll}
\hline & Control over time \\
\cline { 2 - 3 } & High & Low \\
\hline $\begin{array}{l}\text { Perceived competition from } \\
\text { other salesmen: }\end{array}$ & \\
High & $1 \cdot 16(0.68-2 \cdot 00)$ & $1.85(1 \cdot 32-2 \cdot 60)$ \\
Low & $1.20(0.78-1 \cdot 85)$ & 1 (reference) \\
\hline
\end{tabular}

Interacting variables dichotomised, all other variables entered into the model as in table 2 .

Table 4 Final model for symptoms from the shoulders during the past 12 months

\begin{tabular}{|c|c|c|c|c|c|}
\hline Factors: variables & OR & $(95 \% C I)$ & $\begin{array}{l}P \text { value for } \\
\text { logistic } \\
\text { regression }\end{array}$ & $P P R$ & $(95 \% C I)$ \\
\hline \multicolumn{3}{|l|}{ Sex: } & \multicolumn{3}{|l|}{0.004} \\
\hline Men & 1 & & & & \\
\hline Women & $1 \cdot 77$ & $(1 \cdot 20-2 \cdot 62)$ & \multirow{2}{*}{\multicolumn{3}{|c|}{0.024}} \\
\hline \multicolumn{3}{|l|}{ Time spent in the car a week $(\mathrm{h})$ : } & & & \\
\hline$<10$ & 1 & & & & \\
\hline $10-19$ & 1.64 & $(1 \cdot 19-2 \cdot 27)$ & & 1.36 & $(1 \cdot 06-1 \cdot 79)$ \\
\hline $20-29$ & 1.39 & $(0.95-2.03)$ & & $1 \cdot 25$ & $(0.92-1 \cdot 69)$ \\
\hline$\geqslant 30$ & 1.64 & $(0 \cdot 99-2 \cdot 7)$ & & $1 \cdot 38$ & $(0 \cdot 92-2 \cdot 01)$ \\
\hline \multicolumn{3}{|l|}{ Smoking: } & \multicolumn{3}{|l|}{$0 \cdot 045$} \\
\hline Non-smoker & 1 & & & 1 & \\
\hline Exsmoker & $1 \cdot 22$ & $(0 \cdot 87-1 \cdot 70)$ & & $1 \cdot 15$ & $(0 \cdot 88-1 \cdot 50)$ \\
\hline Smoker & 1.46 & $(1.08-1.96)$ & & $1 \cdot 27$ & $(1 \cdot 00-1 \cdot 60)$ \\
\hline \multicolumn{3}{|l|}{ Demands in the work (quartiles): } & \multicolumn{3}{|l|}{0.034} \\
\hline Lowest & 1 & & & 1 & \\
\hline Next to lowest & 0.91 & $(0 \cdot 64-1 \cdot 29)$ & & 0.94 & $(0 \cdot 71-1 \cdot 24)$ \\
\hline Next to highest & 1.07 & $(0 \cdot 76-1 \cdot 51)$ & & $1 \cdot 04$ & $(0 \cdot 79-1 \cdot 37)$ \\
\hline Highest & 1.47 & $(1.05-2.07)$ & & $1 \cdot 25$ & $(0.96-1.62)$ \\
\hline \multirow{2}{*}{\multicolumn{3}{|c|}{$\begin{array}{l}\text { Uncertainty of employment } \\
\text { prospects (quartiles): }\end{array}$}} & \multirow{2}{*}{\multicolumn{3}{|c|}{0.006}} \\
\hline & & & & & \\
\hline Lowest & 1 & & & 1 & \\
\hline Next to lowest & $1 \cdot 20$ & $(0 \cdot 89-1.63)$ & & $1 \cdot 13$ & $(0 \cdot 89-1 \cdot 44)$ \\
\hline Next to highest & $1 \cdot 76$ & $(1 \cdot 26-2 \cdot 46)$ & & $1 \cdot 40$ & $(1 \cdot 09-1 \cdot 80)$ \\
\hline Highest & 1.52 & $(1 \cdot 01-2 \cdot 29)$ & & $1 \cdot 30$ & $(0.95-1 \cdot 77)$ \\
\hline
\end{tabular}

Risk estimates are also controlled for age.

ceived competition three groups were used instead of four because the highest score value was very prevalent.

$P$ values for cross tabulations were calculated from $\chi^{2}$ statistics. Unconditional logistic regression models were fitted with proc probit in SAS, starting with models including all variables which were significant or nearly signifi- cant $(\mathrm{P}<0 \cdot 10)$ in the bivariate tabulations. Variables were successively deleted from the models based on the magnitude of the Wald test $\chi^{2}$ based statistic and considerations as to the scientific relevance of the variable. Age was not significant in any of the models but was kept in the final model for shoulder symptoms because some of the other risk estimates changed more than $10 \%$ when age was included. Interaction terms between the psychosocial variables that were significant in the final main effects model were tested, but were only kept if significant (one of them was).

For each of the final main effects logistic regression models an equivalent Cox's regression model was fitted. ${ }^{17}$

Factor analyses were done in SPSS, all other analyses were done in SAS.

\section{Results}

Table 1 shows the sex and mean age of the study population, and the overall prevalences of symptoms during the past 12 months in neck, shoulders, and low back.

NECK

Table 2 shows the risk estimates from the final main effects model for neck symptoms. Women had an increased risk of neck symptoms during the previous 12 months compared with men. The risk estimates increased monotonically with increasing annual driving distance. Having sedentary work for more than a quarter of the work time was associated with an odds ratio (OR) for neck symptoms of 1.9 or more. The risk estimates increased monotonically or almost monotonically with increasing demands, decreasing control over the time of the work, and increasing competition with other salespeople. A large amount of perceived variation in the work was protective whereas the lower three quartiles had about the same risk estimates (ORs 1.36-1.82).

There was an interaction between control over time and perceived competition from other salespeople $(P=0.016)$, in that only the combination of low control and high competition was associated with an increased risk of neck symptoms (table 3). For the other combinations of control and competition the ORs were close to unity.

\section{SHOULDERS}

Women had a greater prevalence of shoulder symptoms during the previous 12 months than men (table 4). Spending more than 10 hours a week in the car was associated with ORs for shoulder symptoms of 1.39 or more. Smokers and exsmokers had increased risks. Those with the highest job demands had significantly higher risk estimates than the lower three quartiles. Finally, the perception of uncertain employment prospects was associated with increased symptoms.

\section{LOW BACK}

The risk estimates for low back symptoms increased monotonically with increasing annual driving distances over 10000 kilome- 
Table 5 Final model for symptoms from the low back during the past 12 months

\begin{tabular}{|c|c|c|c|c|c|}
\hline Factors: variables & $O R$ & $(95 \% C I)$ & $\begin{array}{l}P \text { value for } \\
\text { logistic } \\
\text { regression }\end{array}$ & $P P R$ & $(95 \% C I)$ \\
\hline \multirow{7}{*}{$\begin{array}{l}\text { Annual driving distance }(\mathrm{km}): \\
<5000 \\
5-10000 \\
10-15000 \\
15-30000 \\
30-50000 \\
>50000\end{array}$} & & & \multirow[t]{7}{*}{0.022} & & \\
\hline & 1 & & & & \\
\hline & 1.40 & $(0 \cdot 65-3 \cdot 04)$ & & $1 \cdot 18$ & $(0 \cdot 68-2.04)$ \\
\hline & 1.89 & $(0.96-3.73)$ & & $1 \cdot 35$ & $(0 \cdot 84-2 \cdot 16)$ \\
\hline & $2 \cdot 23$ & $(1 \cdot 29-3 \cdot 85)$ & & 1.44 & $(0 \cdot 98-2 \cdot 12)$ \\
\hline & $2 \cdot 18$ & $(1 \cdot 28-3 \cdot 72)$ & & 1.43 & $(0.98-2.09)$ \\
\hline & & $(1.54-5.07)$ & & 1.54 & $(1 \cdot 03-2 \cdot 30)$ \\
\hline \multirow{2}{*}{\multicolumn{3}{|c|}{$\begin{array}{l}\text { Sedentary work (proportion of } \\
\text { work time): }\end{array}$}} & \multirow{2}{*}{\multicolumn{2}{|c|}{0.053}} & \\
\hline & & & & & \\
\hline infrequently & 1 & & & 1 & \\
\hline 1 & $1 \cdot 70$ & $(0 \cdot 84-3 \cdot 44)$ & & 1.25 & $(0 \cdot 78-2 \cdot 04)$ \\
\hline$\frac{1}{1}$ & 1.63 & $(0 \cdot 84-3 \cdot 18)$ & & $1 \cdot 25$ & $(0.78-1.98)$ \\
\hline 3 & $1 \cdot 78$ & $(0.91-3.46)$ & & $1 \cdot 28$ & $(0.81-2.03)$ \\
\hline All & $2 \cdot 45$ & $(1 \cdot 24-4 \cdot 85)$ & & 1.42 & $(0 \cdot 89-2 \cdot 26)$ \\
\hline \multicolumn{3}{|l|}{ Smoking: } & \multirow[t]{4}{*}{0.036} & & \\
\hline Non-smoker & 1 & & & 1 & \\
\hline Exsmoker & 1.51 & $(1 \cdot 09-2 \cdot 10)$ & & $1 \cdot 16$ & $(0.96-1.41)$ \\
\hline Smoker & $1 \cdot 31$ & $(0 \cdot 98-1 \cdot 76)$ & & $1 \cdot 11$ & $(0.93-1 \cdot 32)$ \\
\hline \multirow{2}{*}{\multicolumn{3}{|c|}{$\begin{array}{l}\text { Social contact with colleagues } \\
\text { (quartiles): }\end{array}$}} & & & \\
\hline & & & \multirow[t]{5}{*}{0.019} & & \\
\hline Most & 1 & & & 1 & \\
\hline $\begin{array}{l}\text { Next to most } \\
\text { Next to least }\end{array}$ & $1 \cdot 40$ & $(0.99-1.98)$ & & $1 \cdot 15$ & $(0.92-1 \cdot 43)$ \\
\hline $\begin{array}{l}\text { Next to least } \\
\text { Least }\end{array}$ & $1 \cdot 48$ & $(1 \cdot 03-2 \cdot 14)$ & & $1 \cdot 17$ & $(0.93-1 \cdot 46)$ \\
\hline \multirow{2}{*}{\multicolumn{3}{|c|}{$\begin{array}{l}\text { Tendency to feel overworked } \\
\text { (quartiles): }\end{array}$}} & & & $(0.99-1.55)$ \\
\hline & & & \multirow[t]{5}{*}{0.001} & & \\
\hline Least & 1 & & & 1 & \\
\hline Next to least & $1 \cdot 11$ & $(0 \cdot 80-1 \cdot 56)$ & & 1.05 & $(0 \cdot 85-1 \cdot 30)$ \\
\hline Next to most & 1.45 & $(1 \cdot 06-1 \cdot 98)$ & & $1 \cdot 15$ & $(0.95-1.39)$ \\
\hline Most & 2.04 & $(1 \cdot 39-3 \cdot 00)$ & & $1 \cdot 27$ & $(1.02-1.57)$ \\
\hline
\end{tabular}

Risk estimates are also controlled for personal height.

Table 6 Summary of findings by body region

\begin{tabular}{llll} 
& Neck & Shoulders & Low back \\
\hline Factors significant in final models: & & \\
Sex & + & + & + \\
Driving distance & + & + \\
Sedentary work & + & + \\
Time spent in the car & + & + \\
Demands in the work & + & + \\
Variation in the work & & + \\
Control over time & & + \\
Perceived competition & & \\
Smoking & & \\
Uncertain employment prospects & & \\
Social contact with colleagues & \\
Tendency to feel overworked & \\
Height & \\
Factors not significant in final models: & \\
Car equipment & \\
Car price \\
Lifting heavy loads \\
Leisure time sport activities \\
Number of nights spent away from home \\
Type of wage system \\
Type of product sold \\
Age \\
Weight \\
Control over content of the work \\
Support from superiors \\
Work role ambiguity \\
Work role conflict \\
Social network (all dimensions) \\
Confronting, individualistic, and ambitious attitudes \\
Tendency to be late \\
Acceptance seeking \\
Sensitivity to interruptions
\end{tabular}

tres (table 5). Having sedentary work for more than a quarter of the work time was associated with ORs of 1.6 or more, and the risk increased almost monotonically with increasing duration of sedentary work. Smokers and exsmokers were at increased risk. Monotonic increases in the risk estimates were found with decreasing social contact with colleagues and increasing tendency to feel overworked.

The risk estimates for back symptoms increased monotonically with increasing body height (not shown in the table). There was no association between sex and back symptoms.

Table 6 summarises the findings across body regions.

\section{Discussion}

Demands in the work were significantly associated with neck and shoulder symptoms (table 6). High competition, lack of control over time, and lack of variation, were significantly associated with neck symptoms, whereas uncertainty of employment prospects was significantly associated with shoulder symptoms, and lack of social support from colleagues and the tendency to feel overworked were significantly associated with back symptoms. Long driving distances and much sedentary work or long periods spent in the car were associated with neck, shoulder, and low back symptoms. All estimates associated with particular variables were adjusted for the effect of all other variables that were in the model.

Residual confounding has been suggested as an explanation for the relation between demands and musculoskeletal disorders. ${ }^{4}$ It is argued that as high psychosocial job demands are often correlated with high physical load, the associations might be due to lack of precision in the assessment of the physical load. In the present study, apart from driving and sedentary work, the population had little physical load: few salespeople (5\%) lifted more than $400 \mathrm{~kg}$ a day, and none had physically repetitive work. Therefore the likelihood of residual confounding should be low.

Reporting bias has also been suggested as an explanation for the relation between job strain and health outcomes in cross sectional studies. It is argued that people who do not feel well will tend to report more exposures than those who have no symptoms, partly because they perceive their work as stressful because of their symptoms. In the present study validation of self reports by observation was not possible. However, the analyses included several questions which were probably robust to reporting bias-for example, the number of kilometres driven per year.

The questions on number of customer visits, time spent with customers, etc, are probably also robust to reporting bias. They could have been used to assess the psychosocial exposures, but they would only have been proxies for the perceived work strain that we wanted to assess.

A strong argument against the presence of reporting bias in this study is the fact that the intensity of the symptoms was not related to the degree of reported job stressors. If there were reporting bias we would expect it to show up in a dose-response manner.

A main weakness in this and most other studies of musculoskeletal disorders depends on the definition of the outcome. In the strict sense, we assessed the probability of having experienced discomfort or pain in each body region at least once during the past year. Most of the positive responses are due to mild and transient discomfort which may or may not predict more severe long term disease. Previous musculoskeletal disorders have been found to be risk factors for present disorders. It is not clear, however, whether the risk estimates for symptoms reflect the risks of-for example, long term sick leave or early retirement. 
It has recently been debated whether prevalence data should be analysed with logistic regression yielding ORs or with Cox's regression yielding prevalence (proportion) ratios (PPRs). ${ }^{17-19}$ If, in the present context, it is thought that the outcome to be assessed is the risk of experiencing some outcome (here one episode of pain or discomfort) at least once during a period of time (here 12 months), then this cumulative incidence is estimated directly by the prevalence proportion, and the relevant measure of the relative risk is the PPR. As the prevalence of the outcome increases, then the OR tends to be an increasingly poor estimate of the relative risk.

If it is thought that the duration of disease is equal in the exposed and the unexposed group, then in a cross sectional study the prevalence odds ratio (POR) is equal to the ratio of the incidences in the two groups, ${ }^{20}$ and this is usually taken as a good measure of the relative risk. In our case, if the question on symptoms shows the presence of a disease with a defined but unknown duration, which is the same in the exposed and the unexposed groups, then the OR is the relevant measure of the relative risk.

It may make sense to assume that the presence during the past 12 months of musculoskeletal symptoms is indicative of some abnormality of the musculoskeletal system, but it is doubtful whether this definition would be compatible with having a well defined duration. Some authors argue that for musculoskeletal disorders the assumption of similar duration among exposed and unexposed subjects is in general doubtful. ${ }^{18}$ For convenience, and as this is still the usual way to analyse this type of data, we present an analysis based on logistic regression. However, we also present the relative risks estimated as PRs analysed with Cox's regression. ${ }^{17}$

\section{JOB DEMAND-CONTROL-SUPPORT MODEL}

The factors perceived competition and low variation in the work were significantly associated with neck symptoms, as was demand in the work, which was also associated with shoulder symptoms. These findings, and the association between low control and neck symptoms, are consistent with previous studies. ${ }^{4}$ We hypothesised that there might be an interaction (effect modification) between job demands and job control. We found an interaction between one work demand factor, perceived competition, and one control factor, control over time, so that only the combination of low control and high demands was associated with an increased prevalence of neck symptoms. One interpretation of these findings could be that high job demands lead to increased muscle tone, whereas control over time makes it possible to distribute the demands over the work time and thereby introduce rest periods that counteract ill effects.

Lack of social support only seemed to play a part for back disorders. Although one should not over interpret this finding it seems to be consistent with the scientific literature. ${ }^{4}$ Social support from colleagues may entail direct help with specific tasks, or indirectly may increase the salesman's skills so that he can cope with the job demands.

\section{OTHER PSYCHOSOCIAL VARIABLES}

The factor tendency to feel overworked was significantly associated with back symptoms. This was the only personality characteristic that was significant in the analyses. One interpretation would be that people who have a tendency to feel overworked have insufficient skills to manage their job demands. Alternatively, high demands could lead to a feeling of being overworked and thereby, indirectly, to symptoms. The hypotheses on interactions between personality characteristics and psychosocial or physical work variables were not substantiated. The relation between shoulder symptoms and uncertain employment prospects has not been reported before.

\section{PHYSICAL FACTORS}

The risk for neck and back symptoms was high among those who drove long distances and those who had much sedentary work. Both factors were significant after controlling for the other. Lifting was not significantly associated with symptoms, but this should not be regarded as evidence against a relation because there was little difference in loads lifted between salespeople.

In multivariate analyses both physical and psychosocial factors were associated with musculoskeletal symptoms. It is recognised that the cross sectional study design may entail sources of bias. We have argued against the risk estimates being seriously over estimated, but a follow up design would solve this problem more effectively.

1 Riihimäki $H$. Low-back pain, its origin and risk indicators. Scand $\mathcal{F}$ Work Environ Health 1991;17:81-90.

Hagberg M, Wegman DH. Prevalence rates and odds ratio of shoulder-neck diseases in different occupational groups. $\mathrm{Br}$ F Ind Med 1987;44:602-10.

3 Kristensen TS. The demand-control-support model: methodological challenges for future research. Stress Medicine 1995;11:17-26.

4 Bongers PM, de Winter CR, Kompier MAJ, Hildebrandt VH. Psychosocial factors at work and musculoskeletal disease. Scand f Work Environ Health 1993;19:297-312.

5 Ekberg K, Björkqvist B, Malm P, Bjerre-Kiely B, Karlsson $\mathrm{M}$, Axelson $\mathrm{O}$. Case-control study of risk factors for dis$\mathrm{M}$, Axelson $\mathrm{O}$. Case-control study of risk factors for disease in the neck
$1994 ; 51: 262-6$.

6 Bernard B, Sauter S, Fine L, Petersen M, Hales T. Job task and psychosocial risk factors for work-related musculoskeletal disorders among newspaper employees. Scand f Work Environ Health 1994;20:417-26.

7 Houtman ILD, Bongers PM, Smulders PGW, Kompier MAJ. Psychosocial stressors at work and musculoskeletal problems. Scand 7 Work Environ Health 1994;20:139-45.

8 Cooper CL, Payne R, eds. Causes, coping and consequences of stress at work. Chichester, New York, Brisbane, Toronto, Singapore: John Wiley, 1988.

9 Flodmark BT, Aase G. Musculoskeletal symptoms and type A behaviour in blue collar workers. $\mathrm{Br} \mathcal{F}$ Ind Med type A behaviour

10 Kuorinka I, Jonsson B, Kilbom A, Vinterberg H, BieringSørensen F, Andersson G, Jørgensen K. Standardised Nordic questionnaires for the analysis of musculoskeletal Nymptoms. Applied Ergonomics 1987;18:233-7.

11 Karasek RA. Job demands, job decision latitude, and mental strain: implications for job redesign. Administrative Science Quarterly 1979;24:285-308.

12 Marmot MG, Smith GD, Stansfeld S, Patel C, North F, Head $\mathrm{J}$, et al. Health inequalities among British civil servants: the Whitehall II study. Lancet 1991;337:1387-93.

13 Fisher CD, Gitelson R. A meta-analysis of the correlates of role conflict and ambiguity. $\mathcal{F}$ Appl Psychol 1983;68: 320-33.

14 Nord-Larsen M, Ørhede E, Nielsen J, Burr H. 
mellem arbejdsmiljo og helbred. København: Arbejdsmiliofondet, 1992.

15 Östergren P-O. Psychosocial resources and health: with special reference to social network, social support and cardiovascular disease. Malmö, Sweden: Department of Community Health Sciences, Lund University, 1991

16 Siegrist J, Peter R, Junge A, Cremer P, Seidel D. Low status control, high effort at work and ischemic heart disease: prospective evidence from blue-collar men. Soc Sci Med 1990;31:1127-34.
17 Lee J. Odds ratio or relative risk for cross-sectional data? Int f Epidemiol 1994;23:294.

18 Axelson O, Fredriksson M, Ekberg $K$. Use of the prevalence ratio $\mathbf{v}$ the prevalence odds ratio as a measure of risk in cross sectional studies. Occup Environ Med 1994; 51:574.

19 Strömberg U. Prevalence odds ratio $v$ prevalence ratio. Occup Environ Med 1994;51:143-4.

20 Freeman J, Hutchison GB. Prevalence, incidence and duration. Am ₹ Epidemiol 1980;112:707-23.

\section{Rejected manuscripts}

From February 1994, authors whose submitted articles are rejected will be advised of the decision and one copy of the article, together with any reviewers' comments, will be returned to them. The foumal will destroy remaining copies of the article but correspondence and reviewers' comments will be kept. 